\title{
Identification and preservation of the parathyroid gland during total thyroidectomy in dogs with bilateral thyroid carcinoma: a report of six cases
}

\author{
Sho FUKUI ${ }^{1)}$, Yoshifumi ENDO ${ }^{1)}$, Kazuko HIRAYAMA ${ }^{1)}$, Hiroyuki TANIYAMA ${ }^{1)}$ and Tsuyoshi KADOSAWA ${ }^{1) *}$ \\ ${ }^{1)}$ School of Veterinary Medicine, Rakuno Gakuen University, 582 Bunkyodai Midorimachi, Ebetsu, Hokkaido 069-8501, Japan
}

(Received 5 October 2013/Accepted 2 February 2015/Published online in J-STAGE 14 February 2015)

\begin{abstract}
Simultaneous removal of bilateral thyroid tumors was performed while preserving the parathyroid gland in six dogs. At least one external parathyroid gland was identified in all dogs. In five cases, the external parathyroid gland and its blood supply were preserved intact. In one dog, the vessels supplying the external parathyroid gland had been invaded by the tumor, and the gland was thus removed and reimplanted into the sternohyoid muscle. That dog required postoperative treatment with oral calcium gluconate and vitamin $\mathrm{D}_{3}$. Local tumor recurrence was not observed in any of the cases. The mean survival time was 920 days. We found that the external parathyroid gland could be identified and preserved in most dogs undergoing total thyroidectomy.

KEY WORDS: bilateral thyroid carcinoma, canine, hypocalcemia, parathyroid gland identification, parathyroid gland preservation
\end{abstract}

doi: 10.1292/jvms.13-0488; J. Vet. Med. Sci. 77(6): 747-751, 2015

Thyroid tumors account for $1.2-3.8 \%$ of all tumors in dogs $[3,7]$. Carcinomas are more common than adenomas and represent $90 \%$ of thyroid tumors. These tumors typically develop in older dogs; $90 \%$ of affected dogs are older than 7 years of age [22]. Bilateral tumors were reported in as many as $60 \%$ of the dogs in one study [20], but another reported bilateral tumors in only $20 \%$ of dogs [10]. Thyroid carcinomas are considered to be highly malignant, with $16-38 \%$ of affected dogs reported to have evidence of metastasis in the regional lymph nodes or lungs at the time of diagnosis [2, 4, 7]. The median survival time after thyroidectomy is greater than 36 months if the tumor is freely mobile, and 6-12 months if the tumor has invaded the surrounding tissues $[4,10]$.

Treatment of canine thyroid carcinoma depends on the size of the mass, the extent of local invasion, the presence or absence of gross metastatic disease and any clinical signs of thyrotoxicosis. Surgical excision has the best outcome when tumors are freely mobile and have not invaded the deeper tissues $[4,10]$. Thyroidectomy is generally not recommended for bilateral tumors or when there is tumor invasion into the adjacent structures, including the blood vessels, recurrent laryngeal nerves, vagosympathetic trunk, parathyroid glands, and larynx and trachea $[1,11,15]$. However, successful surgical treatment of bilateral thyroid tumors has been reported $[10,16,18,21]$.

In dogs, the presence of a thyroid carcinoma usually prevents identification of the parathyroid gland on the side ipsilateral to the tumor. With bilateral disease, the surgeon needs to perform a total thyroidectomy and to be prepared

*Correspondence to: Kadosawa, T., School of Veterinary Medicine, Rakuno Gakuen University, 582 Bunkyodai Midorimachi, Ebetsu, Hokkaido 069-8501, Japan. e-mail: kado@rakuno.ac.jp (C)2015 The Japanese Society of Veterinary Science

This is an open-access article distributed under the terms of the Creative Commons Attribution Non-Commercial No Derivatives (by-nc-nd) License $<$ http://creativecommons.org/licenses/by-nc-nd/3.0/>. to treat the dog for hypoparathyroidism [18]. However, in humans, techniques for identification and preservation of the parathyroid gland during total thyroidectomy have been established [17]. There are many reports that preservation and/ or autotransplantation of the parathyroid gland can reduce the incidence of post-operative hypocalcemia $[9,12]$. Thus, to minimize post-operative complications, an attempt should be made to identify the parathyroid glands and preserve their blood supply during total thyroidectomy.

The most serious post-operative complication of total thyroidectomy without parathyroid preservation is hypocalcemia. This can be severe and life threatening, and may require intensive monitoring and care followed by prolonged supplementation with calcium and vitamin D. In a study of 15 dogs that underwent total thyroidectomy for mobile thyroid gland tumors, hypocalcemia developed in all nine dogs that underwent complete parathyroidectomies, three of four dogs that underwent autotransplantation and one of two dogs in which a parathyroid gland was preserved [21]. At the end of the study, seven of these dogs still required treatment with calcitriol, with or without supplemental calcium.

There have been reports of surgical treatment of bilateral thyroid tumors in dogs $[10,16,21]$, but a technique for identification and preservation of the parathyroid gland in dogs undergoing total thyroidectomy has not been described. The purpose of this study was to describe the identification and preservation of the parathyroid gland during total thyroidectomy in dogs, to evaluate surgical outcomes and complications associated with this procedure and to provide a basis for prognostic assessment.

The medical records of all dogs diagnosed with bilateral thyroid carcinoma between April 1, 2005 and October 30, 2013 were reviewed. Dogs with freely mobile tumors that were treated by surgical excision and without evidence of metastasis, were included in the study. Six dogs with bilateral thyroid carcinoma met the inclusion criteria. The dogs were all beagles and ranged in age from 5-10 years (mean 
age 8.9 years). Two were intact, and four were spayed females. All six dogs had two palpable thyroid masses, and one had a cough. None of the dogs had abnormal regional lymph nodes (including the retropharyngeal, cranial cervical and mandibular lymph nodes) on palpation or evidence of metastasis on thoracic radiographs.

The tumor volumes, TNM categories and clinical stages are shown in Table 1. Tumor diameters were determined after surgical excision. Tumor volumes were calculated based on tumor diameters. All cases were staged according to the classification system of the World Health Organization [13].

Prior to surgery, serum thyroxine concentrations were recorded for three dogs, and serum calcium concentrations were recorded for all dogs. One dog (case 4) had a high serum thyroxine concentration $(>24.9 \mu \mathrm{g} / \mathrm{d} l$, reference range $1.1-3.6 \mu \mathrm{g} / \mathrm{d} l$ ), but did not have clinical signs of hyperthyroidism. Another (case 5) had a low serum thyroxine concentration $(0.9 \mu \mathrm{g} / \mathrm{d} l)$, but did not have clinical signs of hypothyroidism. Serum thyroxine concentrations were within normal limits in another dog (case 2), and all of the dogs had serum calcium concentrations within the normal reference range.

Thyroidectomy was performed with the patient in dorsal recumbency with a towel under the neck to slightly elevate it. A ventral midline skin incision was made from the larynx to manubrium. The sternohyoid and sternothyroid muscles were separated using blunt dissection and were retracted laterally to expose the thyroid tumors. Each external parathyroid gland was identified as a smooth disc measuring several millimeters in diameter near the cranial pole of the thyroid capsule (Fig. 1). The dark yellow or brownish color of the parathyroid gland differed from the dark red hue of the thyroid tumor. When the external parathyroid gland was not clearly visible, the fibrous tissue covering the cranial pole of the thyroid was dissected to facilitate its identification. To allow preservation of the external parathyroid glands, the tumors were excised using a modified extracapsular technique $[5,6,8,16,18]$. Each identified external parathyroid gland was then bluntly dissected from the thyroid capsule using Metzenbaum scissors and bipolar electrocautery, while the parathyroid branches of the cranial thyroid artery and vein were preserved. The thyroid artery was ligated downstream of the origin of the parathyroid branch with 4-0 absorbable suture, and other small vessels were cauterized with bipolar electrocautery. The tissue downstream of the ligature was then transected, and the thyroid tumor was removed. After thyroidectomy, the musculature was apposed along the midline using 3-0 absorbable suture, and the subcutaneous tissues and skin were closed routinely. Two dogs developed mild postoperative swelling around the surgical wound.

When preservation of the parathyroid vessels was not possible, the parathyroid tissues were minced into approximately 1-mm cubes and reimplanted into muscle [14]. A recipient bed was created in one of the sternohyoid muscles by bluntly dissecting parallel to the muscle fibers, and the minced parathyroid was then implanted into the muscle belly. The muscle was closed with 4-0 absorbable suture.

The gross appearance of the external parathyroid gland
Table 1. Tumor volumes, TNM categories and clinical stages

\begin{tabular}{|c|c|c|c|c|}
\hline & \multicolumn{2}{|c|}{ Tumor Volume $\left(\mathrm{cm}^{3}\right)$} & \multirow{2}{*}{ TNM } & \multirow{2}{*}{ Stage } \\
\hline & Right & Left & & \\
\hline Case 1 & $3.2 * \dagger$ & 63.9 & T3aN0M0 & III \\
\hline Case 2 & $18.2 * \dagger$ & $5.0^{*}$ & T2aN0M0 & II \\
\hline Case 3 & $11.4 * \dagger$ & 26.1 & T2aN0M0 & II \\
\hline Case 4 & $10.4 * *$ & 13.9 & T2aN0M0 & II \\
\hline Case 5 & 7.3 & $5.9 * \dagger$ & T2aN0M0 & II \\
\hline Case 6 & $31.9 * \dagger$ & $27.1 * \dagger$ & T3aN0M0 & III \\
\hline
\end{tabular}

*External parathyroid gland could be identified. † External parathyroid gland could be preserved in situ. \$External parathyroid gland was reimplanted. TNM, Tumor/Node Metastasis/Distant Metastasis.

during surgery is shown in Fig. 1. In four dogs (cases 1, 3,4 and 5), only one external parathyroid gland could be identified, while in the other two dogs (cases 2 and 6), both external parathyroid glands were located. In one of these (case 2), only the right external parathyroid gland was preserved as the left cranial thyroid vein had been invaded by the tumor. In one of the dogs (case 4) in which only one external parathyroid gland was identified, the vessels supplying the gland had been invaded by the tumor. In this dog, the parathyroid gland was excised during bilateral extracapsular thyroidectomy and then dissected free of the thyroid tumor and reimplanted into a recipient bed created in the sternohyoid muscle.

The volumes of the thyroid tumors are shown in Table 1. The mean tumor volume was $17.1 \mathrm{~cm}^{3}$. In 8 of 12 tumors, the ipsilateral external parathyroid gland was identified. In all cases, the external parathyroid gland was identified on the side of the smaller thyroid tumor.

Post-operative serum thyroxine concentrations were within the reference range in five dogs that were treated with oral levothyroxine (5-10 $\mu \mathrm{g} / \mathrm{kg}$ twice daily). One dog (case 4) had a suspected functional thyroid tumor; in this dog, the serum thyroxine concentration was greater than normal, and levothyroxine sodium treatment was discontinued.

Serum calcium concentrations were measured every $6 \mathrm{hr}$ during the first day after surgery and then every 12-24 hr until discharge from the hospital. In four dogs, the serum calcium concentrations remained within the reference range $(9.0-12.0 \mathrm{mg} / \mathrm{d} l)$ after surgery (Fig. 2). In the other two dogs (cases 3 and 4), hypocalcemia was detected after surgery; in one of these (case 3), one external parathyroid gland had been preserved in situ, and in the other (case 4), one external parathyroid gland had been reimplanted. In the dog with the parathyroid gland preserved in situ (case 3), the hypocalcemia was mild, and no treatment was required. In the dog with the reimplanted parathyroid gland (case 4 ), the serum calcium concentration was $8.3 \mathrm{mg} / \mathrm{d} l$ at $26 \mathrm{hr}$ after surgery, and treatment with oral calcium gluconate $(125 \mathrm{mg}$ twice a day) and oral alfacalcidol $(0.005 \mu \mathrm{g} / \mathrm{kg}$ once a day) was initiated. Forty-one days after surgery, the calcium gluconate treatment was discontinued. One hundred and ten days after surgery, the oral alfacalcidol was discontinued, because the serum calcium concentration remained stable.

The condition for being discharged from the hospital was 


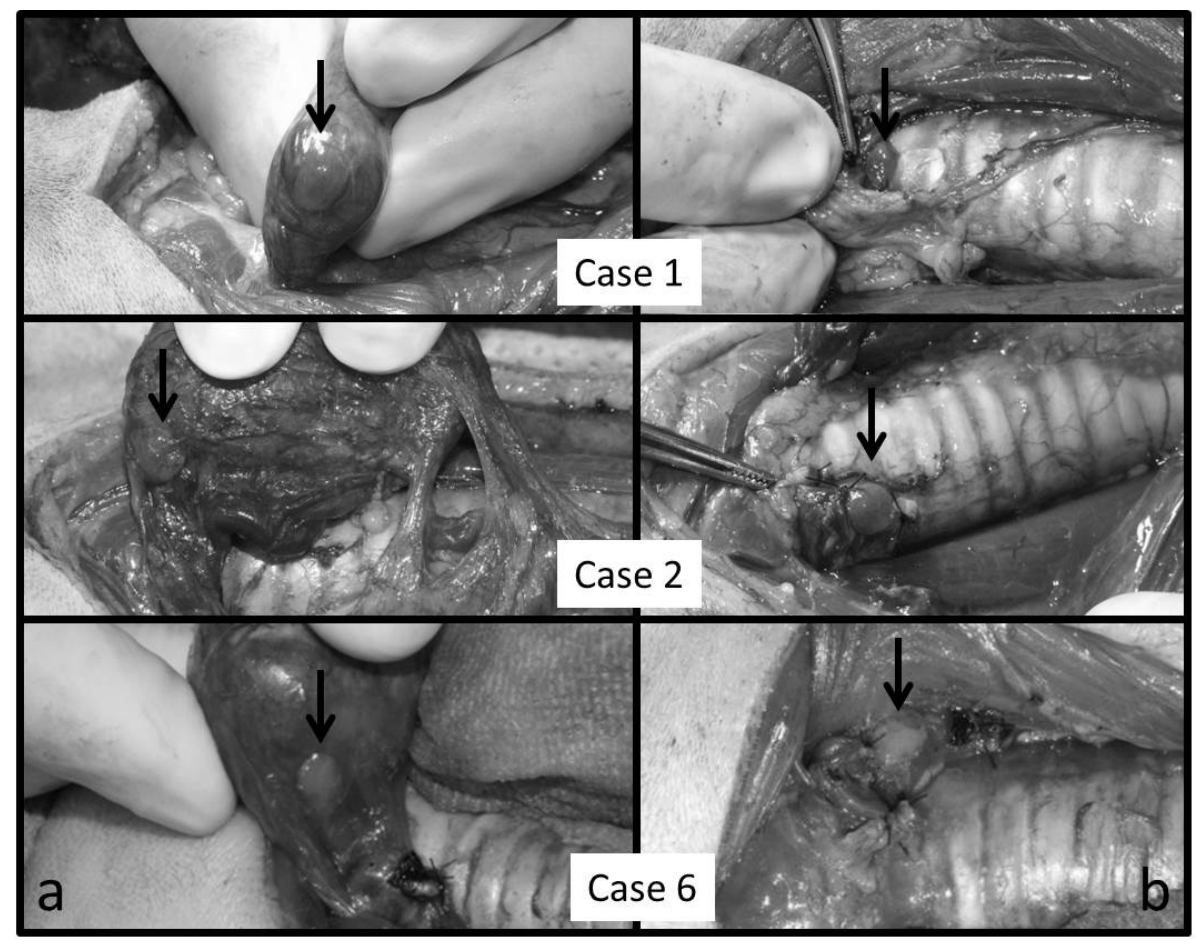

Fig. 1. Intraoperative gross appearance of the external parathyroid gland in situ (arrow). (a) The external parathyroid gland on the surface of the thyroid tumor. (b) The parathyroid gland preserved in situ after excision of the thyroid tumor.

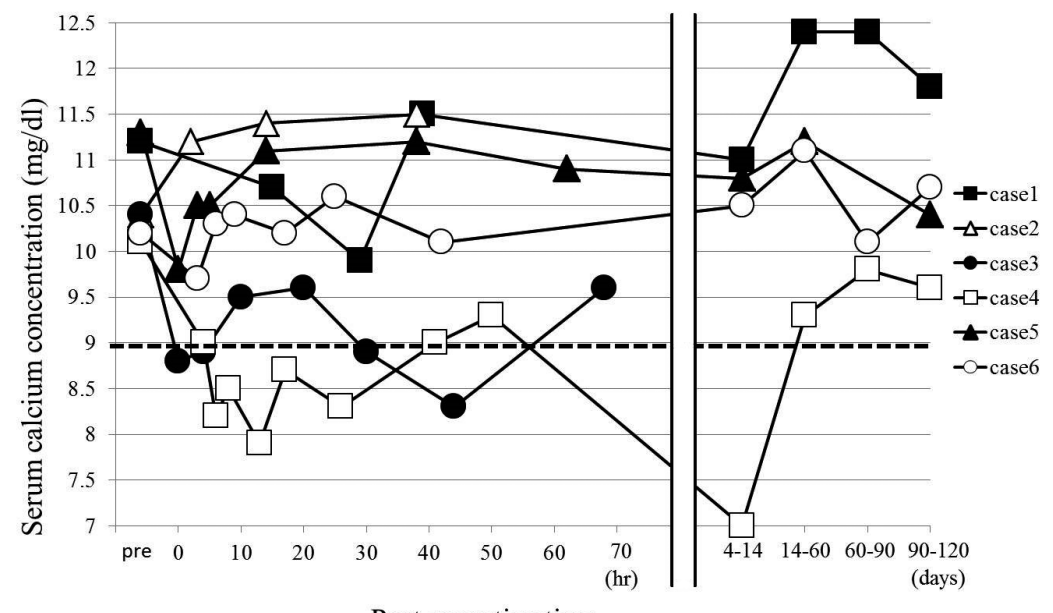

Post operative time

Fig. 2. Serum calcium concentrations in each dog after surgery. The dashed line indicates $9.0 \mathrm{mg} / \mathrm{d} l$, which is the lower limit of the reference range.

that their serum calcium concentration remained stable for more than $36 \mathrm{hr}$. Although case 3 was mildly hypocalcemic at $44 \mathrm{hr}$ after surgery, this dog was discharged $68 \mathrm{hr}$ postoperatively because the hypocalcemia resolved without treatment. Discharge from hospital was on post-operative day 3 (case 6 ), day 4 (cases 1 and 2), day 5 (case 5) or day 6 (cases 3 and 4 ), and the mean duration of the hospital stay was 3.7 days.
All tumors were histologically confirmed to be thyroid follicular cell carcinomas and had locally invaded the blood vessels and thyroid capsule. The surgical margins were infiltrated by tumor cells in two cases (cases 2 and 3). Adjuvant radiation therapy was recommended for these cases, and case 3 received radiation therapy ( 32 Gy in total; 4 Gy fractions over 4 weeks). 
Five dogs were still alive at their last follow-up examination (274, 789, 929, 1,280 and 1,769 days after surgery). Pulmonary metastasis occurred in one dog (case 3) and resulted in death at 477 days after surgery. In the dog with hyperthyroidism (case 4), local recurrence or distant metastases were suspected, but not identified at the final follow-up examination. In the remaining four dogs, no local recurrence or distant metastases were detected at the final follow-up examination. Median survival time was estimated using the Kaplan-Meier method, but the median survival time was not reached. The mean survival time was 920 days.

The parathyroid gland has generally been considered difficult to identify in dogs with thyroid carcinoma [5]. Because the blood supply to the external parathyroid gland might be compromised by the thyroid tumor, detection of the external parathyroid gland on the side ipsilateral to the tumor may be difficult [5]. However, we found that at least one external parathyroid gland could be identified in all of the dogs in our study. The external parathyroid gland was identified as a smooth disc measuring several millimeters in diameter near the cranial pole of the thyroid capsule. In a recent report describing total thyroidectomy in 15 dogs with bilateral thyroid tumors, the external parathyroid gland was not preserved in nine of the cases [21]. However, none of the dogs in our study required total parathyroidectomy.

Acute hypocalcemia due to hypoparathyroidism after total parathyroidectomy may be life threatening [5, 6, 19]. Dogs with acute hypocalcemia should be treated with vitamin $\mathrm{D}_{3}$ and calcium immediately after surgery. In the present study, all five dogs in which an external parathyroid gland was preserved without reimplantation did not require treatment for hypocalcemia. Only one of the dogs required parathyroid reimplantation; this dog experienced postoperative hypocalcemia, which eventually resolved with treatment. In a study of 15 dogs that underwent total thyroidectomy, three of four dogs that underwent reimplantation of an external parathyroid gland required treatment for hypocalcemia [21]. These results suggest that the external parathyroid gland should be preserved in situ when possible to minimize the likelihood of hypocalcemia during the postoperative period.

In a study of cats that underwent reimplantation of an external parathyroid gland after bilateral thyroidectomy, serum calcium concentrations fell below the normal range within $24 \mathrm{hr}$ after surgery and, in most cases, returned to normal within 20 days [14]. It was presumed that the normalization of serum calcium concentrations in these cases likely resulted from revascularization of the parathyroid graft. This suggests that the dog that underwent parathyroid reimplantation in our study regained the ability to maintain normal serum calcium concentrations because of revascularization of the parathyroid graft. The dog received 110 days of treatment for hypocalcemia, because the medication was gradually decreased over a long period of time.

The textbooks suggest that attempts to salvage the parathyroid glands may cause inadvertent seeding of tumor cells at the surgical site [5]; however, no local recurrence was detected at the final follow-up examinations in any of our cases. Previous studies have also not reported an increased rate of local recurrence associated with extracapsular excision of mobile canine thyroid tumors $[10,21]$. Thus, the risk of seeding may be reduced, if careful extracapsular excision is performed.

A median survival time was not reached in our study, but the mean survival time of 920 days is similar to a previously reported survival time [10]. In one study, the median survival time was 7 months, and $47 \%$ of dogs that underwent surgical treatment for thyroid carcinoma died within 2 years after surgery from causes related to primary tumor regrowth or metastasis [7]. Another study reported that the median survival time for dogs that underwent unilateral or bilateral thyroidectomy was more than 36 months, and no cases of local recurrence were observed [10]. In a recent study of bilaterally thyroidectomized dogs, the median survival time after surgery was 38 months, and there were no cases of local recurrence [21]. These results suggest that local control is important in dogs with thyroid tumors. The long survival times and lack of local recurrence seen in the cases that we describe here suggest that the precise preservation of the external parathyroid gland, while maintaining an intact thyroid capsule does not influence local tumor control.

In this study, we found that at least one external parathyroid gland could be identified and preserved in most dogs undergoing total thyroidectomy. This procedure appears to be safe and effective, and reduces the complications associated with the surgical treatment of bilateral thyroid carcinoma in dogs. However, this study only included a small number of cases and the median survival time was not reached, and thus, additional studies should further assess the safety and effectiveness of this technique.

\section{REFERENCES}

1. Barber, L. G. 2007. Thyroid tumors in dogs and cats. Vet. Clin. North Am. Small Anim. Pract. 37: 755-773, vii. [Medline] [CrossRef]

2. Brearley, M. J., Hayes, A. M. and Murphy, S. 1999. Hypofractionated radiation therapy for invasive thyroid carcinoma in dogs: a retrospective analysis of survival. J. Small Anim. Pract. 40: 206-210. [Medline] [CrossRef]

3. Brodey, R. S. and Kelly, D. F. 1968. Thyroid neoplasms in the dog. A clinicopathologic study of fifty-seven cases. Cancer 22: 406-416. [Medline]

4. Carver, J. R., Kapatkin, A. and Patnaik, A. K. 1995. A comparison of medullary thyroid carcinoma and thyroid adenocarcinoma in dogs: a retrospective study of 38 cases. Vet. Surg. 24: 315-319. [Medline] [CrossRef]

5. Ehrhart, N. 2003. Thyroid gland. pp. 1700-1710. In: Textbook of Small Animal Surgery, 3rd ed. (Slatter, D. ed.), Saunders, Philadelphia.

6. Fossum, T. W. 2007. Surgery of the thyroid and parathyroid glands. pp. 602-616. In: Small Animal Surgery, 3rd ed. (Fossum, T. W. ed.), Mosby, St. Louis.

7. Harari, J., Patterson, J. S. and Rosenthal, R. C. 1986. Clinical and pathologic features of thyroid tumors in 26 dogs. $\mathrm{J}$. Am. Vet. Med. Assoc. 188: 1160-1164. [Medline]

8. Hullinger, R. L. 1993. The endocrine system (adrenal gland). pp. 559-585. In: Miller's Anatomy of the Dog, 3rd ed. (Evans, H. E. ed.), Saunders, Philadelphia. 
9. Kim, Y. S. 2012. Impact of preserving the parathyroid glands on hypocalcemia after total thyroidectomy with neck dissection. $J$. Korean Surg. Soc. 83: 75-82. [Medline] [CrossRef]

10. Klein, M. K., Powers, B. E., Withrow, S. J., Curtis, C. R., Straw, R. C., Ogilvie, G. K., Dickinson, K. L., Cooper, M. F. and Baier, M. 1995. Treatment of thyroid carcinoma in dogs by surgical resection alone: 20 cases (1981-1989). J. Am. Vet. Med. Assoc. 206: 1007-1009. [Medline]

11. Liptak, J. M. 2007. Canine thyroid carcinoma. Clin. Tech. Small Anim. Pract. 22: 75-81. [Medline] [CrossRef]

12. Olson, J. A. Jr., DeBenedetti, M. K., Baumann, D. S. and Wells, S. A. Jr. 1996. Parathyroid autotransplantation during thyroidectomy. Results of long-term follow-up. Ann. Surg. 223: 472-478, discussion 478-480. [Medline] [CrossRef]

13. Owen, L. N. 1980. Endocrine glands. pp. 51-53. In: TNM Classification of Tumours in Domestic Animals, 1st ed. (Owen, L. N. ed.), World Health Organization, Geneva.

14. Padgett, S. L., Tobias, K. M., Leathers, C. W. and Wardrop, K. J. 1998. Efficacy of parathyroid gland autotransplantation in maintaining serum calcium concentrations after bilateral thyroparathyroidectomy in cats. J. Am. Anim. Hosp. Assoc. 34: 219-224. [Medline] [CrossRef]

15. Page, R. L. 2007. Tumors of the endocrine system. pp. 423-427. In: Small Animal Clinical Oncology, 4th ed. (Withrow, S. J. and Vail, D. M. eds.), Saunders, St. Louis.
16. Radlinsky, M. G. 2007. Thyroid surgery in dogs and cats. Vet. Clin. North Am. Small Anim. Pract. 37: 789-798, viii. [Medline] [CrossRef]

17. Schwartz, A. E. and Friedman, E. W. 1987. Preservation of the parathyroid glands in total thyroidectomy. Surg. Gynecol. Obstet. 165: 327-332. [Medline]

18. Séguin, B., Brownlee, L. and Walsh, P. J. 2012. Endocrine system. pp. 405-442. In: Veterinary Surgical Oncology, 1st ed. (Kudnig, S. T. and Séguin, B. eds.), Wiley-Blackwell, Ames.

19. Simpson, A. C. and McCown, J. L. 2009. Systemic hypertension in a dog with a functional thyroid gland adenocarcinoma. J. Am. Vet. Med. Assoc. 235: 1474-1479. [Medline] [CrossRef]

20. Théon, A. P., Marks, S. L., Feldman, E. S. and Griffey, S. 2000. Prognostic factors and patterns of treatment failure in dogs with unresectable differentiated thyroid carcinomas treated with megavoltage irradiation. J. Am. Vet. Med. Assoc. 216: 1775-1779. [Medline] [CrossRef]

21. Tuohy, J. L., Worley, D. R. and Withrow, S. J. 2012. Outcome following simultaneous bilateral thyroid lobectomy for treatment of thyroid gland carcinoma in dogs: 15 cases (1994-2010). J. Am. Vet. Med. Assoc. 241: 95-103. [Medline] [CrossRef]

22. Wucherer, K. L. and Wilke, V. 2010. Thyroid cancer in dogs: an update based on 638 cases (1995-2005). J. Am. Anim. Hosp. Assoc. 46: 249-254. [Medline] [CrossRef] 